\title{
Impact of polystyrene beads as a mosquito control measure to supplement lymphatic filariasis elimination activities in Socotra Island, Yemen
}

\author{
A.S. Al-Kubati, ${ }^{1}$ Y. Al Qubati, ${ }^{2}$ W. Ismail, ${ }^{3}$ S.J. Laney, ${ }^{3}$ M. El-Setouhy, ${ }^{4}$ A.M Gad ${ }^{5}$ and R.M.R. Ramzy ${ }^{6}$
}

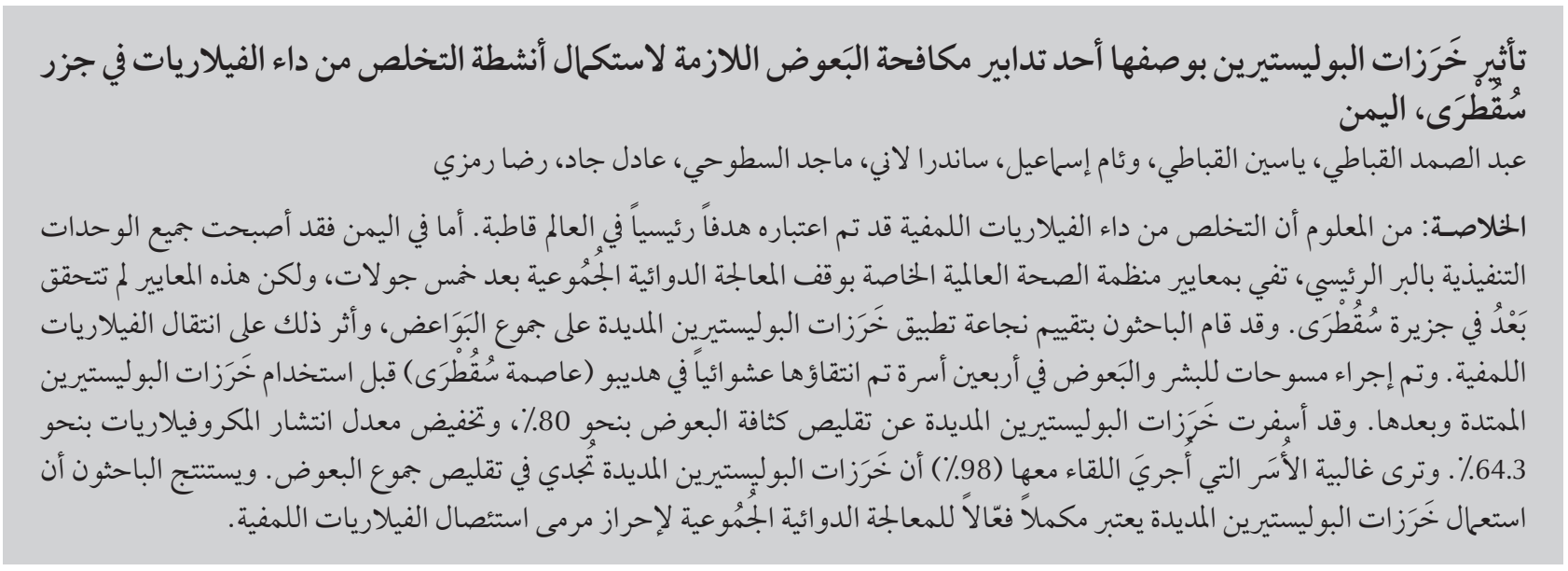

ABSTRACT Lymphatic filariasis (LF) is targeted for worldwide elimination. In Yemen, all mainland implementation units met the WHO criteria for stopping mass drug administration (MDA) after 5 rounds. However, in Socotra Island these criteria were not met. Our study evaluated the efficacy of applying expanded polystyrene beads (EPBs) on the Culex population and the effect on LF transmission. Human and mosquito surveys were conducted in 40 randomly selected households in Hadibo (capital of Socotra) before and after application of EPBs. The EPBs intervention resulted in a reduction in mosquito density of $80 \%$ and a $64.3 \%$ reduction in microfilaria prevalence. The majority of interviewed households (98\%) thought EPBs considerably reduced the mosquito population. After the intervention all collected pools tested negative. Application of EPBs is an effective supplement to MDA for achieving the goal of LF elimination.

Impact des billes de polystyrène en tant que mesure de lutte contre les moustiques en complément des activités d'élimination de la filariose lymphatique sur I'île de Socotra (Yémen)

RÉSUMÉ L'objectif pour la filariose lymphatique est une élimination à l'échelle mondiale. Au Yémen, toutes les unités chargées de la mise en ouvre sur la partie continentale du pays ont rempli les critères de l'Organisation mondiale de la Santé permettant d'interrompre la distribution massive de médicaments après cinq campagnes. Toutefois, dans l'île de Socotra, ces critères n'ont pas été remplis. Notre étude a évalué l'efficacité de l'utilisation de billes de polystyrène expansé sur la population de moustiques Culex et son effet sur la transmission de la filariose lymphatique. Des enquêtes étudiant les moustiques et interrogeant les habitants ont été menées dans 40 ménages sélectionnés aléatoirement à Hadibo, la capitale de Socotra, avant, puis après l'utilisation de billes de polystyrène expansé. L'intervention utilisant des billes de polystyrène expansé a entraîné une réduction de la densité des moustiques de 80 \% et une baisse de la prévalence des microfilaires de 64,3\%. La majorité des ménages interrogés (98\%) pensaient que les billes de polystyrène expansé avaient considérablement réduit la population de moustiques. Après l'intervention, tous les points d'eau analysés étaient négatifs. L'utilisation de billes de polystyrène expansé représente un complément efficace à la distribution massive de médicaments pour atteindre l'objectif d'élimination de la filariose lymphatique.

'Programme for Elimination of Lymphatic Filariasis, Ministry of Public Health, Taiz, Yemen (Correspondence to A.S. Al-Kubati: a-samidku@hotmail.com). ${ }^{2}$ Department of Dermatology, Faculty of Medicine, Taiz University, Taiz, Yemen. ${ }^{3}$ Department of Biological Sciences, Smith College, Northampton, Massachusetts, United States of America. ${ }^{4}$ Department of Community Medicine; ${ }^{5}$ Department of Entomology, Faculty of Medicine, Ain Shams University, Cairo, Egypt. ${ }^{6}$ National Nutrition Institute, Cairo, Egypt.

Received: 20/10/09; accepted: 19/01/10 


\section{Introduction}

Lymphatic filariasis (LF), a vector-born disease caused mainly by the parasite Wuchereria bancrofti, is a major health problem that affects more than 120 million people in 83 tropical and subtropical countries [1-3]. The Global Programme to Eliminate Lymphatic Filariasis was launched in the year 2000 based on the principles of interruption of transmission, and alleviation and prevention of disability due to lymphatic filariasis [2]. Currently, the Global Programme depends largely on repeated annual cycles of mass drug administration (MDA) of albendazole and either diethylcarbamazin or ivermectin to interrupt the transmission of W. bancrofti [4].

In most LF endemic countries, $W$. bancrofti is transmitted by Culex mosquitoes, which typically breed in stagnant and organically polluted water [5]. It appears unlikely that MDA solely would be sufficient for sustained interruption of transmission in highly endemic areas of Culex transmission of LF, due to their high vectorial efficiency [6]. Therefore, application of expanded polystyrene beads (EPBs) to pit latrines and soakage pits has been recommended for prolonged suppression of vector potential [7]. The floating layers of EPBs have been shown to prevent breeding of Culex mosquitoes because they create a physical barrier to egg-laying adults and suffocate larvae and pupae [8]. A study in Zanzibar has showed that the Culex mosquito population decreased by about 98\% after applying EPBs to all the wet pit latrines, without any change in a nearby untreated community [7]. One round of MDA with diethylcarbamazin resulted in decreasing the proportion of mosquitoes with third-stage larvae (L3) resulting in an overall $99.7 \%$ decrease in the number of infective bites per year in the treated area [7].

In Socotra Island, Yemen, LF is endemic and more prevalent in Hadibo, the capital of the island, which is a semi-urban area. Culex quinquefasciatus, the main vector transmitting LF in the Hadibo area, breeds exclusively in outdoor cesspits that are not well covered [Al-Kubati and Gad, unpublished data, 2005]. In 2000, the baseline antigen rate reached $40 \%$ in the Hadibo area [9]. Five rounds of MDA (ivermectin plus albendazole with $>80 \%$ average drug coverage rates of the total population) were completed in 2006 [10]. Monitoring microfilaria (Mf) postMDA showed slow progressive reduction $(36.2 \%)$ in Mf prevalence from $5.8 \%$ in 2003 to $3.7 \%$ in 2006. Such finding indicate the need for further MDA rounds to reach the target of LF elimination $(\mathrm{Mf}<1 \%)$.

Consequently, we aimed to evaluate the efficacy of applying EPBs on the Culex population and the impact on LF transmission. In particular, we measured mosquito density and used molecular xenomonitoring [11] to assess Culex infection rates before and after applying EPBs in the Hadibo area.

\section{Methods}

\section{Study area}

The study was conducted in the Hadibo area, at the northern coast of Socotra Island, starting November 2007. The island (with a population of approximately 48000 according to the 2005census) [12] has an area of 3625 $\mathrm{km}^{2}$, is located in the Indian Ocean $\left(12^{\circ}\right.$ $26^{\prime} \mathrm{N} \& 54^{\circ} 42^{\prime} \mathrm{E}$ ) at the mouth of the Gulf of Aden. The climate is tropical (temperature variation between $22^{\circ} \mathrm{C}$ and $31^{\circ} \mathrm{C}$ in the coastal area, and relative humidity of $50 \%-75 \%$ ) with rainfall of about $170 \mathrm{~mm} /$ year during winter (October-February). During JuneSeptember, monsoonal winds make the island inaccessible except by plane.

Hadibo is inhabited by about 17168 people (2005census) and there is no government environmental sanitation. Each house has its individual latrine pits, which in the majority of cases are inadequately covered or not well closed.
The density of Culex mosquitoes is high and they breed mainly in these cesspits and wet pit latrines.

\section{Study sample}

Human and mosquito surveys were conducted in 40 houses who complained of high mosquito density, selected from 127 houses with inadequately covered cesspits (based on a list of houses at the Roll Back Malaria Programme on the island), before and after application of EPBs. Houses with well-closed cesspits and dry pits (300) were excluded from the study.

\section{Data collection}

The following procedures were carried out: household members in 40 household selected were tested for Mf; a questionnaire for the density of indoor mosquitoes was filled for all 127 households with inadequately covered cesspits (breeding sites); and mosquitoes were collected before the use of EPBs. Mosquito collection and questionnaire surveys were repeated 2 week after the use of EPBs to allow for the mosquito development cycle. For comparison, the Mf survey was repeated 1 year later in the annual Mf monitoring.

\section{Mf surveys}

A total of 421 thick blood smears (60 $\mu \mathrm{L}$ ) were collected about 1 month before the 6 th round of MDA and before the use of EPBs. Thick blood smears ( $n$ = 530) were collected 12 months later and after application of EPBs. Smears were collected at night (between 21:00 and 02:00), air dried, Giemsa-stained and examined microscopically. For quality control, smear slides were examined twice and Mf counted. Results are expressed as the percentage of individuals with Mf and as Mf density.

\section{Mosquito collection and EPBs inter- vention}

To measure the vector density, adult mosquitoes were collected from the 40 selected houses. Two trained staff members, from the malaria control 
programme in Socotra, carried out the spray capture of mosquitoes (total catch) using the spray sheet collection method [13]. Indoor-resting mosquitoes were collected from 1 bedroom per house on $1 \times 2 \mathrm{~m}$ white cotton sheet after knock-down by insecticide. The collection was done in the early morning (around sunrise) during November 2007. Mosquitoes collected from each room/house were counted, pooled and stored in small boxes.

EPBs $(2 \mathrm{~mm})$ were applied to all 127 recorded mosquito-breeding places (cesspits of all houses with inadequate covering) to form a $2-\mathrm{cm}$ thick layer, which required $10 \mathrm{~L} / \mathrm{m}^{2}$ of water surface. Mosquito collection was repeated in the same bedrooms after 2 weeks of the EPBs intervention and compared with the pre-intervention data.

\section{Household questionnaire}

A pretested questionnaire was used to determine whether the household members of the targeted houses would notice a difference in the density of adult mosquito populations before and after the EPBs intervention. Heads of all 127 households were interviewed 1 night before each mosquito collection. The questionnaire included questions about their observation of: mosquito density before the use of EPBs, type of mosquitoes (if known), places of high density, breeding sites and their observation after the EPB application in terms of decrease in mosquito density, level of decrease, period of decrease post-EPBs use, reduction in of nuisance level, resurgence and the householder's evaluation of the benefits of EPBs use.

\section{Detection of Wuchereria bancrofti DNA}

Genomic DNA was isolated from a total of 40 mosquito pools, 20 randomly selected before and after EPBs application from the original 40 houses, according to the method of Ramzy et al.
[14]. W. bancrofti DNA was detected in the isolated DNA using the ligase detection reaction real-time polymerase chain reaction (PCR), which targets the LDR DNA sequence, according the method of Rao et. al., 2006 [15]. Briefly, the LDR real-time system uses two primers (LDR1: ATTTTGATCATCTGGGAACGTTAATA \& LDR2: CGACTGTCTAATCCATTCAGAGTGA) and TaqMan probe (ATCTGCCCATAGAAATAACTACGGTGGATCTCTG) designed by Primer Express software (Applied Biosystems, Foster City, CA). The primers were used unlabelled, but the probe was labelled with the reporter dye FAM (6-carboxyfluorescein) at the 5 ' end and the quencher dye TAMRA (6-carboxytetramethylrhodamine) at the 3 ' end. The real-time PCR reaction was performed with $12.5 \mu \mathrm{L}$ of TaqMan master mix (Applied Biosystems) along with $450 \mathrm{nmol} / \mathrm{L}$ of each primer and $125 \mathrm{nmol} / \mathrm{L}$ probe in a final volume of $25 \mu \mathrm{L}$. Two microliters of gDNA isolated from mosquito pools were mixed with the PCR master mix in 96well MicroAmp optical plates (Applied Biosystems). Thermal cycling and data analysis were done with an ABI Prism 7000 instrument using SDS software (Applied Biosystems). Water was used as a negative control and DNA from $W$. bancroffi Mf served as a positive control sample in all real-time PCR runs. All real-time PCR reactions were carried out in duplicate, and cycle threshold values for each sample were determined according to the manufacturer's instructions.

\section{Statistical analysis}

The PoolScreen2 software [16], available upon request from the Department of Biostatistics and Division of Geographic Medicine, University of Alabama at Birmingham, United States of America, was used to estimate the maximum likelihood of $W$. bancrofti infection in collected mosquitoes at the 95\% confidence level.
Reduction levels (RL) for Mf prevalence and Mf load were calculated as below $(\mathrm{T}=$ treatment $)$.

$$
\mathrm{RL}=\frac{\text { pre }-\mathrm{T} \text { value }- \text { post }-\mathrm{T} \text { value }}{\text { pre }-\mathrm{T} \text { value }} 100
$$

Data were analysed with SPSS for Windows, version 11.0.1). The MannWhitney 2-tailed rank sum test was used for comparisons of means limited to 2 groups.

\section{Results}

\section{Pre-intervention mosquito density}

Culex quinquefasciatus was present in all houses investigated. The total number of mosquitoes collected was 4268 adults with a mean of 107 mosquitoes per room per night; the number of pre-intervention mosquitoes collected ranged from 22 to 420 mosquitoes per room per night.

\section{Impact of EPBs on adult Culex quinquefasciatus population}

The total number of mosquitoes collected from all rooms decreased to 837 adults (19.6\% relative to preintervention) with a mean of 21 per room per night; the number ranged from 3 to 68 mosquitoes per room per night. The EPBs intervention resulted in an overall reduction in mosquito density of $80 \%(P=0.02)$. Through follow-up and observation, the reduction appeared to last for more than 3 months after the application of the EPBs.

\section{Questionnaire data}

All 127 households were interviewed both before and after the intervention. The questionnaire data indicated that $97 \%$ of the household members noted a decrease in the density of the mosquito population; $96 \%$ thought the intervention resulted in a $50 \%$ reduction in mosquito density. Of the interviewed household members, $98 \%$ considered that the use of polystyrene beads was 


\begin{tabular}{|c|c|c|c|c|c|c|}
\hline Opinion & $\begin{array}{c}\text { High mosquito } \\
\text { density before } \\
\text { EPBs }\end{array}$ & $\begin{array}{l}\text { Density } \\
\text { reduction } \\
\text { after EPBs }\end{array}$ & $\begin{array}{l}\text { Estimated \% } \\
\text { of mosquito } \\
\text { reduction }\end{array}$ & $\begin{array}{c}\text { Time of noted } \\
\text { reduction after EPBs } \\
\text { application }\end{array}$ & $\begin{array}{l}\text { Nuisance } \\
\text { reduction }\end{array}$ & $\begin{array}{l}\text { Evaluation of } \\
\text { polystyrene use }\end{array}$ \\
\hline Agree No. (\%) & 127 (100) & 123 (96.8) & $\begin{array}{c}50 \%: 122(96) \\
25 \%: 1(0.8)\end{array}$ & $\begin{array}{c}2 \text { days: } 2 \text { (1.6) } \\
1 \text { week: } 114(89.8) \\
2 \text { weeks: } 9 \text { (7.1) }\end{array}$ & $123(96.8)$ & Good: 124 (97.6) \\
\hline Disagree No. (\%) & 0 & $2(1.6)$ & 0 & 0 & $2(1.6)$ & 0 \\
\hline $\begin{array}{c}\text { No comment } \\
\text { No. }(\%)\end{array}$ & 0 & $2(1.6)$ & $4(3.2)$ & $2(1.6)$ & $2(1.6)$ & $3(2.4)$ \\
\hline
\end{tabular}

a good intervention for reducing mosquito populations (Table 1).

\section{Impact of vector control on filariasis transmission}

\section{Mosquito infection}

Mosquitoes collected before the EPBs intervention were sorted $(n=4268)$, and males and mosquito species other than Culex quinquefasciatus were discarded ( $n=176$ mosquitoes). A total of 450 randomly selected, mosquitoes were tested in 20 pools (a pool/house) by the LDR real-time PCR. Fifteen (15) of the tested pools contained 25 mosquitoes and the other 5 pools contained different numbers $(15,15,16$, 10 and 19 mosquitoes). Three pools had positive PCR results (Table 2). The minimum mosquito infection rate (providing that a positive pool contained one infected mosquito) was calculated as $0.66 \%$. The Poolscreen algorithm estimated the maximum likelihood of mosquito infection rate as $0.73 \%$ (95\% CI: $0.14 \%-2.10 \%)$.

Following application of the EPBs, after discarding males and mosquito species other than Culex quinquefasciatus from the mosquitoes collected from the 20 houses, a total of 281 mosquitoes were tested by the LDR real-time PCR in 20 pools ( $1-25$ mosquitoes/pool). All pools were negative. The Poolscreen algorithm estimated the maximum likelihood of mosquito infection rate as 0.00\% (95\% CI: 0.00\%-0.68\%).

\section{Human infection}

Mf prevalence decreased from 1.4\% before the EPBs intervention to $0.5 \%$ 12 months after the EPBs application (64.3\% reduction). In the same manner, the Mf density decreased from $53 \mathrm{mf} /$ $\mathrm{mL}$ to $28 \mathrm{mf} / \mathrm{mL}$ (47.12\% reduction).

\section{Discussion}

The current strategy for LF elimination, based on interruption of transmission, depends mainly on drug distribution. However, a WHO consultation [17] encouraged integrated vector control measures, especially in areas where dramatic reduction in the prevalence of infection following multiple MDA rounds is not observed. In the present study, we supplemented MDA with application of EPBs as a measure for mosquito control.

In our study application of EPBs resulted in a large decrease of Culex mosquitoes (19.6\% relative to preintervention). The decrease in the mosquito population was maintained over 3 months, which would lower human exposure to filariasis transmission. Of great interest is our observation that $\mathrm{Mf}$ prevalence among household members decreased by $64.3 \%$ consequent to supplementing MDA with the application of EPBs. In previous years, Mf prevalence had decreased by $38.3 \%$ (from $6 \%$ to $3.7 \%$ ) and $35.1 \%$ (from $3.7 \%$ to $2.4 \%$ ) following yearly MDA in Socotra. Thus, the use of EPBs as a vector control measure had a synergetic effect on reducing $L F$ transmission leading to timely disease elimination.

Despite the progress made towards LF elimination in Socotra, several factors work against achieving LF elimination using only 5 MDA rounds, including the relatively high infection rates $[40 \%$ antigenaemia by

\begin{tabular}{|c|c|c|c|c|c|}
\hline Period & $\begin{array}{c}\text { No. of } \\
\text { mosquitoes }\end{array}$ & $\begin{array}{c}\text { No. of } \\
\text { mosquito pools } \\
\text { examined }^{\mathrm{a}}\end{array}$ & $\begin{array}{l}\text { No. of positive } \\
\text { mosquito pools }\end{array}$ & $\underset{(\%)^{\mathbf{b}}}{\operatorname{Minimum} \mathrm{MI} \text { rate }}$ & $\begin{array}{c}\text { Maximum } \\
\text { likelihood of MI } \\
(95 \% \mathrm{Cl})(\%)\end{array}$ \\
\hline Pre-EPBs application & 450 & 20 & 3 & 0.66 & $0.73(0.14-2.10)$ \\
\hline Post-EPBs application & 281 & 20 & 0 & 0.00 & $0.00(0.00-0.68)$ \\
\hline
\end{tabular}

aPre-EPBs mosquito pools contained 10-25 mosquitoes/pool, and post-EPBs mosquito pools contained 1-25 mosquitoes/pool.

${ }^{b}$ Minimum MI rate providing that a positive pool contains at least 1 positive mosquito.

$P C R=$ polymerase chain reaction; $\mathrm{MI}=$ mosquito infection; $\mathrm{Cl}=$ confidence interval . 
the immunochromatographic (ICT) filariasis test] prior to starting MDA. Therefore, the findings of our study suggest that while the national programme focus will be primarily on achieving high rates of MDA coverage, integration of other vector control measures will be necessary. However, wide application of EPBs as an effective vector control measure faces some challenges. For example, finding all the wet cesspits infested with Culex quinquefasciatus is not easy. Furthermore, periodic emptying of cesspits and the presence of strong seasonal wind may remove the polystyrene beads and would likely reduce the effectiveness of a single EPBs treatment.
Nevertheless, our finding that $98 \%$ of the participantsinterviewed appreciated the use of EPBs for mosquito control is encouraging and indicates that the community would willingly support the wide use of such a control measure.

\section{Conclusion}

Our study in Hadibo area (known for high LF infection rate before MDA) clearly showed that application of EPBs in major cesspits together with MDA resulted in a dramatic reduction of Mf prevalence $($ to $<1 \%)$. Wide application of such an effective strategy in Socotra would ensure successful LF elimination in the island.

\section{Acknowledgements}

This study received technical and financial support from the joint WHO Eastern Mediterranean Region (EMRO), Division of Communicable Diseases (DCD) and the WHO Special Programme for Research and Training in Tropical Diseases (TDR): The EMRO/TDR Small Grants Scheme for Operational Research in Tropical and other Communicable Diseases.

\section{References}

1. Michael E, Bundy DAP, Grenfell BT. Re-assessing the global prevalence and distribution of lymphatic filariasis. Parasitology, 1996, 112:409-428.

2. Ottesen EA et al. Strategies and tools for the control/elimination of lymphatic filariasis. Bulletin of the World Health Organization, 1997, 75:491-503.

3. Zagaria N, Savioli L. Elimination of Lymphatic Filariasis: A public health challenge. Annals of Tropical Medicine and Parasitology, 2002, 96(Suppl. 2):3-13.

4. Molyneux DH, Zagaria N. Lymphatic filariasis elimination; progress in global programme development. Annals of Tropical Medicine and Parasitology, 2002, 96(Suppl. 2):15-40.

5. Curtis CF, Feachem RG. Sanitation and Culex pipiens mosquitoes: a brief review. Journal of Tropical Medicine and Hygiene, 1981, 84:17-25.

6. Burkot TR et al. The argument for integrating vector control with multiple drug administration campaigns to ensure elimination of lymphatic filariasis. Filaria Journal, 2006, 5:10.

7. Maxwell CA et al. Control of Bancroftian filariasis by integrating therapy with vector control using polystyrene beads in wet pit latrines. Transactions of the Royal Society of Tropical Medicine and Hygiene, 1990, 84:709-714.

8. Curtis CF et al. Use of floating layers of polystyrene beads to control populations of the filaria vector Culex quinquefasciatus. Annals of Tropical Medicine and Parasitology, 2002, 96(Suppl. 2):97-104.

9. National Leprosy Elimination Programe: Annual Report 2000 [Lymphatic Filariasis Report]. Taiz, Yemen, Ministry of Public Health, 2000:21-22.
10. Global programme to eliminate lymphatic filariasis. Weekly Epidemiological Records, 2007, 82:361-380.

11. Ramzy RM et al. Effect of yearly mass drug administration with diethylcarbamazine and albendazole on bancroftian filariasis in Egypt: a comprehensive assessment. Lancet, 2006, 367:992-999.

12. Census 2004. Final results. Sana'a, Central Statistical Organization of Yemen, General Population, Housing and Establishment, 2004.

13. Manual on practical entomology in malaria [Part 2]. Geneva, World Health Organization, 1975:6-12.

14. Ramzy RM et al. A polymerase chain reaction-based assay for detection of Wuchereria bancrofti in human blood and Culex pipiens. Transactions of the Royal Society of Tropical Medicine and Hygiene, 1997, 91:156-160.

15. Rao RU et al. A real-time PCR-based assay for detection of Wuchereria bancrofti DNA in blood and mosquitoes. American Journal of Tropical Medicine and Hygiene, 2006, 74(5):826832.

16. Helmy $\mathrm{H}$ et al. Test strip detection of Wuchereria bancrofti amplified DNA in wild-caught Culex pipiens and estimation of infection rate by a PoolScreen algorithm. Tropical Medicine \& International Health, 2004, 9:158-163.

17. Defining the roles of vector control and xenomonitoring in the Global Programme to Eliminate Lymphatic Filariasis. Report of the informal consultation held at WHO/HQ, Geneva, 29-31 January 2002. Geneva, World Health Organization, 2002 (WHO/ CDS/CPE/PVC /2002,3). 